\title{
QUANDO OS ESTUDANTES VÃO À ESCOLA DA EJA: DIFICULDADES ENCONTRADAS
}

\author{
Ana Paula Santos Vasconcelos ${ }^{1}$ \\ https://orcid.org/0000-0003-0038-3518
}

Antônio Amorim² https://orcid.org/0000-0003-3236-9139

Maria da Conceição Alves Ferreira ${ }^{3}$ https://orcid.org/0000-0002-9408-2750

RESUMO: Este estudo originou-se a partir de uma pesquisa realizada para analisar os principais problemas que o público da Educação de Jovens e Adultos - EJA encontram e impactam na sua permanência nos espaços educacionais quando decidem ingressar nesta modalidade de ensino. Trazemos como problema: quais são os problemas encontrados pelos estudantes da EJA quando se dirigem a escola? O objetivo principal desta investigação foi analisar os principais problemas que surgem quando os estudantes da EJA buscam a escola. Por meio de uma abordagem qualitativa e de uma análise autobiográfica procuramos entender a trajetória dos estudantes do curso de Segurança do Trabalho do PROEJA que acontece no Instituto Federal de Educação (IFBA), Campus Santo Amaro. Os resultados apresentados foram os seguintes: observamos os professores sem a formação necessária para trabalhar com a EJA; os estudantes relatam que a EJA ofertada na instituição de ensino técnico federal é diferente da oferta que receberam no ensino municipal ou estadual; o sentido social da modalidade não é tratado em sala de aula.

PALAVRAS-CHAVE: Escola da EJA, Estudantes, Dificuldades.

1 Mestranda do programa de Mestrado Profissional de Educação de Jovens e Adultos - MPEJA da Universidade Estadual da Bahia - UNEB. Salvador - Bahia - Brasil anavazkoncelos@gmail.com

2 Doutorado pela Universidade de Barcelona da Espanha (UB). Professor Titular Pleno do Departamento de Educação do Campus I, da Universidade do Estado da Bahia (UNEB). Salvador - Bahia - Brasil antonioamorim52@gmail.com

3 Doutora em Educação pela Universidade do Estado da Bahia. Professora adjunta da UNEB, atuando no Programa de Mestrado Profissional em Educação de Jovens e Adultos - MPEJA. Salvador - Bahia - Brasil consinha@terra.com.br 


\section{WHEN STUDENTS GO TO EJA'S SCHOOL: DIFFICULTIES ENCOUNTERED}

ABSTRACT: This study originated from a survey carried out to analyze the main problems that the public of Youth and Adult Education - EJA encounter and impact on their permanence in educational spaces when they decide to enter this type of education. We bring as a problem: what are the problems encountered by EJA students when they go to school? The main objective of this investigation was to analyze the main problems that arise when EJA students go to school. Through a qualitative approach and an autobiographical analysis, we seek to understand the trajectory of students in the PROEJA Workplace Safety course that takes place at the Federal Institute of Education (IFBA), Campus Santo Amaro. The results presented were the following: we observed teachers without the necessary training to work with EJA; students report that the EJA offered in the federal technical education institution is different from the offer they received in municipal or state education; the social sense of the modality is not dealt with in the classroom.KEYWORDS: EJA School, Students, Difficulties.

PALABRAS CLAVE: Escuela EJA, Alumnos, Dificultades.

\section{CUANDO LOS ESTUDIANTES VAN A LA ESCUELA DE EJA: DIFICULTADES ENCONTRADAS}

RESUMEN: Este estudio se originó a partir de una encuesta realizada para analizar los principales problemas que encuentra el público de Educación de Jóvenes y Adultos EJA y su impacto en su permanencia en los espacios educativos cuando decide ingresar a este tipo de educación. Traemos como problema: ¿Cuáles son los problemas que encuentran los estudiantes de EJA cuando van a la escuela? El principal objetivo de esta investigación fue analizar los principales problemas que surgen cuando los estudiantes de EJA buscan escuela. A través de un enfoque cualitativo y un análisis autobiográfico, buscamos comprender la trayectoria de los estudiantes en el curso de Seguridad Laboral PROEJA que se realiza en el Instituto Federal de Educación (IFBA), Campus Santo Amaro. Los resultados presentados fueron los siguientes: observamos docentes sin la formación necesaria para trabajar con EJA; los estudiantes informan que la EJA ofrecida en la institución de educación técnica federal es diferente a la oferta que recibieron en la educación municipal o estatal; el sentido social de la modalidad no se trata en el aula.

KEYWORDS: EJA School, Students, Difficulties. 
Introdução

O presente estudo trata da temática Público da Educação de Jovens e Adultos - EJA e os desafios que eles encontram ao retornar aos espaços educacionais. Observamos como análise principal os problemas encontrados por pessoas que depois de um período afastado do ambiente educacional retornam às escolas, trazendo consigo seus objetivos e história de vida. Escolhemos o tema a fim de refletir a respeito dos problemas enfrentados pelo público da EJA quando retornam aos espaços formais de aprendizagem.

Pessoas com histórias diversas buscam os espaços educacionais da EJA, todos os anos, porém, as histórias que as levaram até ali são diferentes, assim como os objetivos que norteiam esse retorno também são. Investigar os problemas referentes aos processos educacionais da EJA e as pessoas que estão inseridas nela, nos leva diretamente às questões que levaram ao retorno e afastamento destas pessoas à escola.

Conhecer os estudantes da EJA e sua trajetória pessoal e educacional é tão importante quanto investigar a respeito dos processos de ensino-aprendizagem nesta modalidade de ensino. Assim como acontece com todos os estudantes, em qualquer nível de ensino, cada estudante da EJA traz consigo uma história e uma perspectiva em relação ao que a educação vai lhe retornar. Além disso, eles têm propósitos que caminham junto a suas buscas a esses propósitos pode girar em torno de questões profissionais, pessoais ou educacionais.

Além de conhecer o estudante, analisar a modalidade a partir da perspectiva discente temos acesso a situações educacionais e pessoais intrínsecas que nos faz despertar a atenção para questões que podem ser específicas da modalidade e dos estudantes que a compõem. Sejam estas questões de ensino e aprendizagem, da relação interpessoal entre aluno e professor, sobre os impactos encontrados ou até mesmo sobre a relação que o próprio estudante cria entre suas próprias versões de: pai e/ou mãe, trabalhador e/ou estudante. Neste sentido é que trazemos para a discussão o seguinte problema: quais são as dificuldades enfrentadas pelos sujeitos da EJA quando se dirigem a escola?

Para consolidar a investigação sobre o que acontece quando o público da EJA vai à escola da EJA e procurar respostas para o problema destacado, definimos como o objetivo geral: analisar as principais questões que surgem quando os sujeitos da EJA buscam a escola. As questões que surgiram ao longo desta investigação, foram fundamentais para que pudéssemos atingir os objetivos do trabalho. A partir da triangulação de dados da qual nos apropriamos, fizemos a análise das informações necessárias para embasar a investigação. 
Diante desse contexto, trouxemos como objetivos específicos, que procuram respostas para os detalhes da nossa análise, os seguintes: identificar os problemas de cunho educacional, social e cultural que interferem na permanência dos estudantes da EJA na escola; investigar quem são essas pessoas; refletir sobre as possíveis soluções para resolver os problemas de ensino encontrados nas escolas pelos estudantes da EJA.

A partir dessa questão, apresentamos também, para contextualizar o tema, um breve panorama da EJA, que nos ajudou a perceber o âmbito educacional em que o sujeito em questão está inserido e de que forma a política pública que estabeleceu essa modalidade surgiu. Além disso, apresentamos os propósitos da modalidade e sua representatividade.

A respeitos das políticas públicas educacionais de atendimentos aos jovens e adultos, segundo Haddad e Di Pierro diz que:

No âmbito nacional, a EJA se manteve na agenda de políticas educacionais no início do terceiro milênio por diferentes razões. De um lado, a oferta pública de oportunidades de alfabetização, elevação de escolaridade e formação para o trabalho tornou-se uma imposição legal pela Constituição de 1988 e a Lei de Diretrizes e Bases da Educação Nacional (LDBEN) de 1996, ao reconhecerem o direito público subjetivo dos jovens, adultos e idosos ao estudo (2015, p.206).

Como abordado anteriormente, a oferta da EJA é uma política pública educacional de atendimento às pessoas que não tiveram acesso aos estudos da educação básica, no período em que idade condizia com a série. Esta política tem o propósito de acolher e reinserir nos espaços educacionais as pessoas que desejam ter acesso ou dar continuidade aos estudos que foram interrompidos. Após alguns anos de luta, a EJA vem ocupando o seu lugar não somente enquanto política pública, mas também, enquanto uma causa que devemos lutar a favor e apoiar, independente de sermos estudantes dela ou não.

Ter acesso ou retornar aos espaços educacionais, após alguns anos, não é uma iniciativa simples. O preconceito, a falta de oportunidade, a não representatividade nestes espaços, a dinâmica da vida das pessoas, a logística diária muitas vezes atrapalha os processos das pessoas que buscam retornar suas atividades estudantis. Por estas e outras questões, devemos lutar pela EJA e pelas pessoas que nela está, uma vez que capacitar as pessoas permite que elas tenham mais oportunidades.

Apesar do foco desta pesquisa ser os estudantes e sua experiência 
estudantil diária, não podemos deixar de trazer para esse contexto um pouco do papel do professor neste processo, já que o mesmo precisa assumir uma dinâmica importante neste cenário, servindo referência para os alunos. Assim, como em qualquer outra modalidade de ensino, o papel do professor/educador deve ser o de estimulador e mediador do processo de ensino-aprendizagem dos seus alunos. Eles devem comprometer-se não somente com o seu papel profissional, mas também, procurar apoiar a causa educacional que é um dever de todos.

Com base nos estudos sobre os estudantes da EJA, podemos notar que eles trazem em sua trajetória registros de dificuldade de acesso aos espaços educacionais, assim como a vulnerabilidade social em que vivem. Um histórico de fatores que levam essas pessoas a desistir da educação regular durante um período de suas vidas. Os docentes que assumem um compromisso com a EJA, assim como os que atuam em outras modalidades de ensino, precisam ter consciência da necessidade de pensar e de utilizar mecanismos que especificam suas práticas docentes para os estudantes. Métodos e práticas que estimulem os estudantes a permanecerem em sala de aula, não somente no sentido de cumprir a carga-horária, mas também, de ressignificar este espaço educacional. Apropriar-se de práticas docentes que tenham a ver com a realidade do público com o qual estão trabalhando e planejar aulas na qual a realidade do aluno esteja intrínseca, entendemos que isto seja o mínimo necessário para que o processo de ensino-aprendizagem dos sujeitos da EJA seja significativo.

Identificar as possíveis vertentes que abrem portas para uma análise sobre a EJA e definir como objeto de estudo o sujeito estudante é estar disposto a analisar diversos pontos de vista. Afinal, não estamos falando apenas dos aspectos da modalidade e sim da experiência das pessoas que dela fazem parte enquanto estudante. As questões que foram trazidas pelos estudantes não podem ser comparadas, em linhas gerais, com as questões do cenário educacional geral, pois, elas são específicas do sujeito estudante da EJA. Esses sujeitos traçam a sua trajetória estudantil, a partir das situações vividas no frequentar os espaços educacionais, na luta e na resistência cotidiana revelada pelo espaço educacional.

Abordar a EJA a partir desta perspectiva também pode influenciar nas práticas pedagógicas, assim como nos procedimentos metodológicos pensados e utilizados pelos professores. Essas influências não devem resultar em mudanças apenas para os estudantes investigados, elas devem atender aos demais conforme as necessidades dos outros espaços educacionais e das outras pessoas. 
Assim como nas outras modalidades de ensino, os sujeitos que ingressam na EJA têm objetivos, sejam eles profissionais, pessoais ou educacionais. Além disso, a educação é um direito de todos e a EJA é como uma possibilidade de reingresso nos espaços educacionais para aqueles que, por algum motivo, não deram segmento aos estudos no período em que sua idade condizia com a série.

[...] o papel da educação é ainda mais importante uma vez que não deve perder o seu foco diante de tanta contrainformação cabendo a ela o papel de desenvolver uma leitura emancipatória que possibilite compreender a realidade não de forma fragmentária, mas em seu sentido global. Sendo assim, como visto, o pensamento de Paulo Freire tem muito a contribuir a uma educação que valorize os sujeitos e dê a possibilidade de emancipação (SUESS; LEITE, 2017, p.103).

De acordo com os autores Suess e Leite, procurar a escola ou retornar aos estudos quando se faz parte de uma camada social desfavorecida é uma tarefa complexa, pois além da rotina diária de sala de aula, os estudantes ainda precisam reafirmar a viabilidade desta luta, todos os dias, para que ela seja reconhecida e fortalecida.

É a partir dessas e de outras questões que apresentamos relatos de dezessete estudantes sobre sua trajetória na EJA e de que forma ela interfere na vida estudantil, social e profissional. Este panorama é importante para que possamos contextualizar as situações cotidianas destas pessoas, com a atual situação da EJA no Brasil. Assim, seguindo os procedimentos metodológicos desta investigação, abordamos as principais questões da EJA e também destacamos a partir dos relatos dos participantes as situações mais comuns entre aqueles que retornam aos espaços educacionais depois de um período afastado.

A análise das questões dessa modalidade de ensino a partir do relato dos estudantes é uma iniciativa que tem fundamento na definição da política pública que define a EJA. É desta forma que percebemos o quanto é importante a voz dos estudantes e, além disso, o quanto suas histórias podem influenciar nas mudanças que a EJA precisa passar para de fato atender as pessoas que lutam por seu reconhecimento e efeitos na sociedade e âmbito educacional.

Vivemos em uma nação onde os problemas sociais atingem as camadas populares, de forma mais rápida, principalmente os desprivilegiados, isso torna maior a rede de fortalecimento dessa causa social. Apesar dos desafios 
encontrados pelos docentes e discentes da EJA em sua caminhada acadêmica, o próprio legado da modalidade faz com que essas pessoas sigam lutando pela modalidade e direito a ela.

Questões sociais, políticas e financeiras, todos os dias estão diretamente ligadas às vidas das pessoas, e estas em alguns momentos podem assumir um papel decisivo na trajetória das pessoas. Em alguma fase da vida as pessoas sentem necessidade de aprender mais sobre uma determinada coisa e acreditamos que essa motivação também traz muita gente de volta para as salas de aula. Na EJA podemos encontrar exemplos de pessoas que vão em busca do direito a perspectiva de melhora em algum aspecto.

\section{Procedimentos metodológicos da investigação}

Apresentamos aqui os procedimentos metodológicos que norteiam a partir do rigor científico este estudo. Abordamos o caminho reflexivo pelo qual procuramos destacar a abordagem, o dispositivo estratégico, destacando os sujeitos, o local, os instrumentos, as etapas e o procedimento de análise da investigação. Optamos pela abordagem qualitativa que, de acordo com Minayo (2008), nos permite analisar dados de forma triangulada, através de questionário, entrevista e observação. Além disso, oferece as condições dinâmicas para compreendermos os pormenores do contexto estudado.

A pesquisa foi realizada no Instituto Federal de Educação, Ciência e Tecnologia da Bahia - IFBA, Campus Santo Amaro. A unidade conta atualmente com 3 pavilhões, onde são ofertados cursos nas modalidades de ensino integrado (técnico e médio), subsequente, superior e EJA. Os professores dividem-se em suas áreas específicas em cada modalidade. O campus funciona nos três turnos, sendo que durante os turnos da manhã e tarde apenas os alunos da modalidade integrada têm aula.

Os prédios do IFBA Campus Santo Amaro encontram-se em boas condições de uso. Trata-se de uma instituição de ensino federal, onde não se têm muitos problemas em relação aos recursos educacionais. Laboratórios, salas de aula, materiais de apoio pedagógico, tudo está disponível na medida do possível para que todos os alunos de todas as modalidades tenham acesso aos mesmos recursos.

Os sujeitos investigados são estudantes da EJA do Curso de Segurança do Trabalho que foi implantado no IFBA através do Programa Nacional de Integração da Educação Profissional com a Educação Básica na Modalidade de Educação de Jovens e Adultos - PROEJA. O curso divide-se em 4 módulos, 
um por semestre, onde as disciplinas ofertadas em cada semestre a partir do segundo tem como pré-requisito disciplinas do semestre anterior. A turma escolhida para trabalhar nesta pesquisa foi a do quarto módulo, por já trazer na bagagem uma experiência mais ampla sobre o curso em relação às turmas dos módulos anteriores.

A turma é formada por 17 alunos, sendo estes: 4 homens e 13 mulheres, com idade entre 24 e 52 anos. Deste grupo de pessoas, 7 não residem na cidade de Santo Amaro e sim na região circunvizinha. Além disso, os dados da nossa pesquisa informaram que 12 dessas pessoas trabalham em empregos formais e/ou informais e 5 delas não executam nenhum tipo de atividade remunerada.

Esta é uma pesquisa de abordagem qualitativa, onde o procedimento metodológico de investigação utilizado é a autobiografia. Quanto ao instrumento de análise utilizamos entrevista semiestruturada, questionário e observação para triangular os dados e informações. Foram realizados quatro encontros para que pudéssemos realizar a pesquisa. Em um desses encontros foi realizada a entrevista e aplicação de questionários, nos outros as observações.

A pesquisa de abordagem qualitativa segundo Minayo (2013) é entendida como aquele que se ocupa do nível subjetivo e relacional da realidade social e é tratado por meio da história, do universo, dos significados, dos motivos, das crenças, dos valores e das atitudes dos atores sociais, permitindo assim que a subjetividade das informações tenha um papel fundamental no estudo.

Isso não quer dizer que ela não deve seguir o rigor científico, ao contrário disso existem parâmetros para que este tipo de pesquisa seja realizado. Esses parâmetros estão diretamente relacionados ao método e aos procedimentos de coleta de dados e análise das informações. Se fizermos um panorama sobre as práticas de pesquisa, suas referências e consolidação, iremos perceber que elas estabelecem rupturas e reconstruções. Deste modo, a abordagem qualitativa ao mesmo tempo que nos distancia das teorias, nos faz buscá-las no momento que vamos analisar e fundamentar os resultados que encontramos.

Estamos falando de um cenário complexo, no qual o objeto em estudo tem papel fundamental na conexão que será estabelecida entre o ponto de vista do pesquisador, a teoria e a metodologia científica. Escolher a abordagem qualitativa para esta investigação foi fundamental, uma vez que apenas dados tabelados não iriam nos fazer analisar a temática da forma que analisamos e nem mesmo chegar às considerações que chegamos. Por isso, as informações obtidas nas entrevistas semiestruturadas apresentaram de forma própria a 
legitimidade dos dados dos questionários.

Adotamos como procedimento estratégico a investigação autobiográfica, esta foi uma experiência primária para os estudantes que foram investigados. Segundo Passegi:

[...] a pessoa, ao narrar sua própria história, procura dar sentido às suas experiências e nesse percurso, constrói outra representação de si: reinventa-se. Assim, como esta é significante para o sujeito investigado é de grande importância para o sujeito investigador. [...] a cada nova versão da história a experiência é ressignificada. E essa é uma razão para a pesquisa educacional, pois nos conduz a buscar relações entre viver e narrar, ação e reflexão, narrativa, linguagem, reflexividade autobiográfica e consciência histórica [...] (2010, p.1-2).

Foi exatamente como conduzimos esta investigação, nos reinventando e reconsiderando cada detalhe da história que foi destacada pelos estudantes da EJA, de forma que essas informações norteasse os resultados das análises.

Também, os autores Nóvoa e Finger (2010) expressam que a pesquisa autobiográfica no âmbito educacional tomou corpo científico a partir do século XX e, ao ser colocada em prática, despertou interesses por conta da epistemologia que ela traz. Lembrando que ela foi idealizada por estudiosos no final do século XIX com o intuito de permitir novos pensamentos em relação ao momento positivista que a história vivenciava. Isso explica a influência que este método de pesquisa tem e de que forma ele surge como uma alternativa quando desejamos realizar um tipo de pesquisa que tem como fonte principal o indivíduo investigado.

A pesquisa autobiográfica permite obter informações diretas a partir do ponto de vista de quem estamos investigando. Além disso, possibilita ter acesso a informações subjetivas que em alguns casos nos faz enxergar a partir de uma perspectiva diferente da que tínhamos quando definimos um problema. Essa mudança pode interferir nos parâmetros da investigação e não devemos enxergar isso com estranheza, já que quando iniciamos uma pesquisa ela é inédita e precisamos ter maturidade para aguardar dela as respostas que já esperamos e as que não pensamos como possibilidade tendo em vista também que na pesquisa autobiográfica o método satisfaz com informações o pesquisador e o sujeito pesquisado.

Para utilizar-se do método autobiográfico deve-se ter uma certa responsabilidade, por isso, Ferraroti (2010) destaca que ao utilizá-lo de forma 
inapropriada pode-se mudar completamente o seu sentido. Afinal, a intenção do mesmo não é somente reunir informações. Utilizar-se dos relatos dispostos para reforçar hipóteses e tentar reafirmá-las a partir disso é como distorcer o principal objetivo deste método. Para estabelecer-se como método, a autobiografia passou por alguns momentos de negação e invalidação, porém sua unicidade faz com que ele seja essencial nos casos das pesquisas que necessitam de informações específicas do pesquisado.

Sobre as etapas da pesquisa autobiográfica, Ferraroti (2010) revela que devemos nos apropriar e fazer uso dos materiais primários que são identificadas pelas narrativas e autobiografias que conseguimos ter acesso durante o processo de entrevistas e os de biografia secundária que são as fotografias, alguns documentos oficiais, recortes de jornais e revistas e até mesmo mídias como áudios e filmagens. Outros métodos supervalorizam estes materiais secundários enquanto a autobiografia para ser original tem estes materiais descartados pelos pesquisadores.

Em relação aos instrumentos utilizados na entrevista semiestruturada, mantivemos todas as perguntas em um único bloco, com perguntas subjetivas para que pudéssemos classificar a nossa investigação. As perguntas tinham como foco principal a investigação a respeito do sujeito da EJA, com perguntas que norteava a análise sobre quem são essas pessoas e da trajetória delas até ingressar nos espaços educacionais por meio da EJA e como era o seu processo de permanência e resistência nestes espaços. O que as levavam a lutar pelo direito à educação e, além disso, investigar quais eram os entraves e desafios que estas pessoas enfrentaram e enfrentam para manter-se nesta posição de estudante.

Para Minayo (2016), todo pesquisador deve especular todas as vertentes e possibilidades do que ele quer pesquisar, não precisa ter medo do surgimento de novas questões e deve sempre ter curiosidade. Seguindo esta teoria, esta pesquisa foi realizada com base nos procedimentos científicos e metodológicos que uma pesquisa científica precisa atender, trazendo as informações investigadas em forma de relato, questionários e observação.

Neste caso, o questionário da investigação era composto pelas seguintes perguntas: 1- Qual a sua idade; 2 - onde você mora e como faz para vir para aula; 3 - você trabalha? Caso a resposta seja "sim", informe se é formal ou não; 4 - quantos anos você ficou sem estudar até chegar nesse curso; 5 - o que te fez interromper os estudos; 6 - o que te trouxe de volta a sala de aula. 
Quadro 1 - Apresentação dos participantes da pesquisa.

\begin{tabular}{|c|c|c|l|c|}
\hline NOME & IDADE & SEXO & \multicolumn{1}{|c|}{ CIDADE } & EMPREGADO \\
\hline Pedro Augosto & 24 & f & Santo Amaro & Sim \\
\hline Paulo & 32 & $\mathbf{m}$ & Santo Amaro & Sim \\
\hline Marina & 33 & $\mathrm{f}$ & São Francisco do Conde & Não \\
\hline Cássia & 52 & $\mathrm{~m}$ & Santo Amaro & Sim \\
\hline Joana & 49 & $\mathrm{f}$ & Santo Amaro & Sim \\
\hline Roberto & 50 & $\mathrm{f}$ & São Francisco do Conde & Sim \\
\hline Joelma & 31 & $\mathrm{f}$ & São Francisco do Conde & Não \\
\hline Paloma & 24 & $\mathrm{f}$ & Santo Amaro & Não \\
\hline Luíza & 27 & $\mathrm{~m}$ & Santo Amaro & Sim \\
\hline Andréia & 38 & $\mathrm{f}$ & Oliveira dos Campinhos & Não \\
\hline Gabriela & 39 & $\mathrm{f}$ & Santo Amaro & Sim \\
\hline Romário & 39 & $\mathrm{~m}$ & Santo Amaro & Sim \\
\hline Rita & 47 & $\mathrm{f}$ & Santo Amaro & Sim \\
\hline Cármem & 40 & $\mathrm{f}$ & Oliveira dos Campinhos & Sim \\
\hline Ilma & 41 & $\mathrm{f}$ & São Francisco do Conde & Sim \\
\hline Roselane & 26 & $\mathrm{f}$ & Santo Amaro & Sim \\
\hline Maricélia & 25 & $\mathrm{f}$ & São Francisco do Conde & Não \\
\hline
\end{tabular}

Fonte: elaborado pelos autores, 2019.

O quadro acima mostra um recorte da realidade da EJA no Brasil, onde pessoas com idades diferentes fazem parte da mesma turma em um curso profissionalizante. Deste modo podemos ver a diversidade que a EJA atende, tanto os professores, quando os estudantes passam por um processo de resistência para aprender a lidar uns com os outros. As demandas, as histórias de vida, os propósitos, circulam nestas salas de aula a todo o momento, em conjunto com os conteúdos dispostos e trabalhados.

\section{Situação da EJA na contemporaneidade}

De acordo com dados da Pesquisa Nacional por Amostra de Domicílio - PENAD (2017), são mais de 11,8 milhões de analfabetos no Brasil, sendo que entre esses, os cidadãos autodeclarados pretos e pardos são maioria. Por cauda do preconceito e desigualdade as pessoas menos favorecidas acabam tendo cada vez menos oportunidades. Esta foi uma pesquisa realizada em 2017 e os dados mostraram que as pessoas que se encaixam no padrão de analfabetos em situação de vulnerabilidade social têm mais de 15 anos para estudantes do ensino fundamental e 18 para estudantes do ensino médio e só frequentaram a escola até o nível de ensino Fundamental I. Não concluindo assim as etapas necessárias para obter a educação básica.

A educação é um direito de todos, porém sabemos que nem 
todas as pessoas tiveram a oportunidade de frequentar os espaços educacionais na idade estabelecida pelo estado como adequada, isso pode ter dificultado a trajetória educacional, profissional e social destas pessoas, fazendo com que eles fossem cada vez mais em busca de atividades não formais para suprir suas necessidades de sustento e as de seus familiares.

De acordo com Charlot (2000), o sujeito traz consigo desejos e faz parte de uma sociedade que tem uma historicidade, apesar de viver em relação com outras pessoas são os seus desejos individuais que os norteiam. Se pensarmos que este sujeito é um ser social e que está inserido em uma determinada configuração familiar e vive em contato com uma situação social que condiz com a classe em que está inserido, que os terna singular.

A partir dessa análise podemos perceber que a vivência forma o ser e sua história, o que justifica o perfil dos estudantes da EJA. Dessa forma, com o surgimento da modalidade, muitos sujeitos tiveram o direito de retornar aos espaços educacionais, dessa forma, podendo retomar as buscas dos seus objetivos em seu tempo.

A EJA é uma modalidade de ensino básico que foi criada com o propósito de garantir o direito ao ensino fundamental obrigatório e gratuito em especial para os sujeitos que não cursaram na idade própria. Ela garante a todo cidadão maior de 18 anos que já está afastado da escola e não concluiu o Ensino Fundamental I no período em que a legislação estabelece como adequado, retorne aos espaços educacionais.

A EJA vem passando por um processo de reafirmação contínua em suas bases que a estabelece e práticas pedagógicas que a faz acontecer. Essa reafirmação acontece em paralelo ao seu processo de resistência, para que ela continue atendendo aos objetivos das pessoas que a procura. A resistência na EJA é realizada pelos estudantes que não desistem do seu direito de continuar os estudos e também pelos professores que acreditam nas possibilidades que a modalidade oferece e não desistem de ressignificar a experiência educacional dos estudantes através do ensino.

No cenário educacional, social e político contemporâneo, podemos perceber os problemas que a EJA passou e vem passando enquanto política pública educacional, enquanto modalidade de ensino e para sustentar esses desafios e se fortalecer cada vez mais. Assim podemos começar a analisar de que forma é ofertado este ensino. Estes problemas podem ser reconhecidos desde a falta de formação docente continuada para qualificar profissionais para trabalhar com os estudantes dessa modalidade até a falta de recursos públicos financeiros destinados a ela. 
A partir da análise de Santos (2019), com base na centralidade estabelecida nas lutas contra a dominação, exclusão e epistemologias do Sul, deveríamos buscar qual o sentido da palavra "Luta". Ele diz que não podemos responder isso de forma geral, pois cada luta se estabelece a partir de um conjunto de questões e, em cada conjuntura que esta luta está se representando existem as pessoas que vão em busca de melhorias e pessoas que não tem ao menos conhecimento dos seus direitos de lutar.

Ao refletir sobre a teoria de Santos (2019) a respeito da palavra "luta" e de seus prováveis participantes, podemos enxergar a situação da afirmação da EJA, onde pessoas de um lado lutam para que ela seja valorizada e do outro, pessoas a ignora.

Não podemos pensar em analisar a EJA sem pensar em Paulo Freire, pois essa política no Brasil ganhou forças graças a sua luta e dedicação. Ele acreditava que todas as pessoas têm direito a educação e não somente a isso, acreditava que todo sujeito tem direito de educação de qualidade e além disso, ser reconhecido dentro do espaço educacional enquanto pessoa, além de estudante. Para Freire a história de vida das pessoas diz muito sobre sua trajetória acadêmica seja em qualquer modalidade, e para os estudantes da EJA esse é um fator muito importante, que os representa.

Combater o analfabetismo sempre foi o legado de Freire, e isso para ele não era uma tarefa que deixava os sujeitos da EJA em condição de coitados que não sabiam lutar por seus direitos educacionais, mas sim era a uma forma de conscientizar estas pessoas a reconhecer-se como oprimidos para que pudessem reagir e ir em busca dos seus objetivos. Sendo assim ele defende que:

Quem, melhor que os oprimidos, se encontrará preparado para entender o significado terrível de uma sociedade opressora? Quem sentirá, melhor que eles, os efeitos da opressão? Quem, mais que eles, para ir compreendendo a necessidade da libertação? Libertação a que não chegarão pelo acaso, mas pela práxis de sua busca; pelo conhecimento e reconhecimento da necessidade de lutar por ela. Luta que, pela finalidade que Ihe derem os oprimidos, será um ato de amor, com o qual se oporão ao desamor contido na violência dos opressores, até mesmo quando está se revista da falsa generosidade referida. (FREIRE, 2013, p.3 1)

Na citação acima, Paulo Freire aborda o papel do estudante no cenário educacional da EJA. O quanto é importante ele perceber e analisar seus processos educacionais para assim lutar por melhoras. A partir do momento 
em que o indivíduo toma conhecimento do contexto em que está inserido, de quais são as oportunidades e direitos que eles deveriam ter, ele consegue se posicionar diante das situações de desvantagens que irão passar.

Da mesma forma que Paulo Freire demarcou o lugar da EJA no Brasil, os sujeitos estudantes também foram em busca desse reconhecimento de lugar e foi a partir de algumas práticas docentes e discentes que a EJA se estabeleceu enquanto política pública emancipadora. Embora este processo de emancipação através da educação ainda seja uma caminhada longa, já podemos ver mais os movimentos de fortalecimento e representatividade para que essa ação vire rotina.

\section{Quem são os estudantes da EJA atualmente}

A partir dos dados coletados no questionário realizamos as entrevistas, nela tivemos acesso a informações que não seria disposto no questionário ainda que ele tivesse apenas perguntas subjetivas. As pessoas relataram suas experiências de vida na entrevista e isso fez com que pudéssemos perceber o quanto é importante o direito de fala, ainda que a entrevista tenha sido semiestruturada para nos nortear cientificamente quanto ao procedimento de investigação.

Responder a idade, onde mora, se estão trabalhando ou não, não é suficiente para que possamos compreender, para além dos interesses da pesquisa, a realidade destas pessoas. Foi no momento da entrevista que tivemos acesso às questões talvez nunca expostas em sala de aula pelos estudantes. Foi a partir daquele momento que pensamos o quanto foi rica a pesquisa autobiográfica, tanto para o pesquisador, quanto para o sujeito pesquisado, que tem a oportunidade de falar sobre si e ao mesmo tempo fazer uma autoanálise sobre seu contexto de vida.

Os estudantes da EJA definiram que se sentem importantes quando têm o direito de fala, e depois que se sentiram confiantes para falar, disseram também que gostariam de ter essa oportunidade mais vezes. Gostaram de falar sobre suas virtudes e complicações ao retornar para a escola, mas disseram também que ela é um espaço de refúgio para eles.

Assim, percebemos que a vida escolar e pessoal dos estudantes da EJA nunca caminha a passos largos, uma vez que a busca pelos espaços educacionais se justifica, para a melhoria das condições de vida social e profissional, sendo que as desistências dos espaços educacionais acontecem, na maioria das vezes, por questões que estão envolvidas na demanda social que essas pessoas representam. 
Para Paiva (2019), todas as pessoas têm direito a educação, isso é o básico da dignidade. Além disso, para ela, a educação não se realiza apenas nos espaços educacionais, ela é estabelecida por uma troca entre a academia e a contribuição social que os sujeitos trazem para a sala de aula. Viver refém da política e da sociedade é uma situação em que se encontra a maioria dos sujeitos da EJA, porém, esse não é um motivo para que eles estejam impedidos de acontecer.

A reflexão que a autora faz em relação à contribuição dos próprios estudantes para a caracterização da modalidade é muito rica, pois são essas histórias e contextos que fazem a EJA ser como é. Não podemos deixar de especificar o perfil desses sujeitos, discentes e docentes, uma vez que a autora fala sobre o fato de que há lugar para pessoas de qualquer raça, gênero, idade.

Machado (2016) alerta quem são de fato essas pessoas, observando por meio de uma investigação que compara o perfil dos estudantes da EJA em 20 anos. Na investigação, ela traz dados que apontam o número de estudantes maiores de 18 anos que não concluíram o ensino fundamental e tiveram a EJA como alternativa para continuar os estudos.

Da mesma forma que, segundo dados do IBGE (2019) aponta para os 900 mil que evadiram nessa faixa etária do ensino fundamental e não estão matriculados na EJA e o sistema de ensino não dá conta.

Assim, ela pode chamar atenção também para identificar que os jovens inseridos na EJA, pela faixa etária, são justamente as pessoas que deveriam estar ingressando ou concluindo o ensino superior e, estes não demonstram essa perspectiva em alguns casos, entendem que a EJA é a sua alternativa limite para os estudos.

Dessa forma, conclui em sua análise que o país que está entre uma das dez potências mundiais e tem metade da sua população sem a educação básica. Estão entre eles os jovens das periferias que por intolerância das instituições ou problemas sociais foram expulsos da escola e também os adultos e idosos que por falta de incentivo e motivação estão cada vez menos fazendo parte das turmas da EJA. Aí podemos ver o princípio da juvenilização da EJA.

Ainda, segundo Machado (2016) são estas pessoas que muitas das vezes sofrem a desvalorização da sociedade, começando pela a falta de instrução para reivindicar os seus direitos enquanto pessoa e enquanto estudante. Estes, em muitos casos, não cobram aos órgãos governamentais por melhorias no sistema de ensino, não fazem filas nas portas das escolas exigindo mais vagas, nem transporte escolar, não expõem os maus-tratos sofridos dentro das escolas e em outros espaços sociais. Além disso, quando ingressam na EJA, não 
reivindicam currículos mais apropriados para a modalidade.

Toda essa movimentação, que não parte dessas pessoas, está diretamente associada a suas causas mais urgentes, como por exemplo, ter que lutar pela sua sobrevivência e a dos seus familiares. Quando não encontram o apoio que buscam nos espaços educacionais, os sujeitos acabam abandonando essa causa educacional e vão em busca, apenas, do que para eles, no momento se torna prioridade.

Se olharmos para os quatro cantos do cenário da EJA encontraremos pessoas que tiveram sonhos interrompidos, que sobrevivem em situação de total vulnerabilidade social, que não têm perspectiva de melhora em suas vidas e buscam a modalidade como espaço de convivência com outras pessoas e que estão no mesmo contexto. Assim, também encontraremos pessoas que mesmo antes de retomar os estudos, percebem que alguma coisa não está correta e que eles têm direito de continuar. E retornam, lutam, permanecem, enxergam possibilidades e compram essa causa.

Foi a partir desses estudos e dos relatos dos estudantes aqui investigados, que podemos compreender quem são os sujeitos estudantes da EJA, o que eles encontram quando retornam a este espaço educacional. Por essas e outras questões, não podemos justificar apenas como falta de interesse a evasão escolar das pessoas de classe social inferior. Além disso, defendemos que as pessoas que retornam aos espaços educacionais, não devem ser julgadas como sendo pessoas que apresentam dificuldades de aprendizagem.

Os estudantes do Curso Profissionalizante de Segurança do Trabalho do IFBA, Campus Santo Amaro, o qual foi investigado, relataram que pelo fato do mesmo acontecer em uma instituição de ensino federal, onde ofertam cursos de nível superior, integrado e subsequente, sentem-se minoria. "Sempre que acontece um evento na escola, a gente nem fica sabendo. Quando os alunos das outras turmas vêm avisar nas salas passam direto da nossa." (Aluno 3).

Eles também relataram não gostar de participar de reuniões que envolvem toda instituição, como por exemplo: as reuniões de Diretório Acadêmico. Disse um aluno investigado "Quando os professores avisam que vai ter palestra a gente vai embora mais cedo ou chega quando termina, por que alguns assuntos a gente não têm acesso antes e chega lá não estamos por dentro do que está se passando. Não vale a pena ir só para fazer tumulto". (Aluno 12).

Sobre a falta de especialização dos professores para trabalhar com a EJA, não quer dizer que eles não são qualificados. Para suas áreas de graduação, muitos são mestres ou doutores, mas essa especialização acaba favorecendo aos estudantes das modalidades: integrada, subsequente e superior. Já para 
os estudantes investigados isso nem sempre é uma vantagem, pois não há professor com especialização em EJA que dão aula no curso de Segurança do Trabalho.

Alguns professores têm noção deste problema e procuram adaptar-se a modalidade, ajudam os alunos a permanecerem e se ajudam enquanto prática docente. Enquanto isso, outros tentam reutilizar conteúdos que utilizam nas outras modalidades na EJA, tornando a construção confusa em sala de aula.

Por esse motivo relatou um estudante entrevistado "Eu sinto vergonha de dizer que tenho dúvida sobre uma atividade que alguns professores ensinam, porque quando eles pedem para gente fazer já dizem que os alunos do integrado fizeram aquilo em 2 minutos" (Aluno 10).

Essa comparação entre os perfis de estudantes, que são completamente diferentes é uma ação antiprofissional que o professor realiza, que afasta cada vez mais do estudante da EJA e de qualquer outra modalidade de ensino a possibilidade de querer acertar quando tem dificuldade.

Para esses estudantes entrevistados, nesta instituição de ensino não encontram problemas como falta a de infraestrutura nos prédios, de material didático disponibilizado pelo governo ou falta de professor em sala de aula. Porém, encontram problemas como a discriminação praticada por alguns estudantes das outras modalidades e a desvalorização humana efetivada por alguns professores.

Realizamos toda essa caminhada para desenvolver nossa investigação, trazendo questões como a EJA, o estudante que faz parte dela, a educação no país e os desafios que esses sujeitos enfrentam para permanecer nos espaços educacionais. É por estes e outros motivos que em alguns casos, os estudantes da EJA se sentem de mãos atadas para resolver problemas educacionais que eles enxergam, mas não conseguem articular uma possibilidade de solução.

\section{Resultados da investigação autobiográfica}

A partir da análise das informações registradas durante a pesquisa, podemos observar de imediato, que todo sujeito da EJA tem suas peculiaridades, sendo que não é a modalidade que os torna iguais na forma de pensar, de agir e na efetivação de seus objetivos de vida. Investigar primeiramente as pessoas que compõem o cenário da EJA é uma porta de entrada para tentarmos entender as questões que norteiam essas pessoas e suas vidas profissionais e sociais.

No momento em que iniciamos as observações em sala de aula, po- 
demos ver que os alunos se intimidaram com a presença de um pesquisador no ambiente, pois saber que estava sendo observado para eles era invasivo, somente após o segundo encontro é que se sentiram à vontade para participar das entrevistas. Foi assim que um estudante empolgado com a ação disse "É a primeira vez na minha vida que eu vou ser entrevistado, nunca pensei que fosse tão importante assim." (Estudante 17).

Podemos observar na análise das respostas do questionário e da entrevista que $80 \%$ dos investigados trabalham, e desses apenas $30 \%$ têm a carteira assinada, os demais realizam atividades remuneradas sem vínculo empregatício. Além disso, os outros $20 \%$ relataram que não estão encontrando trabalho nem mesmo informal.

Por isso, veem na EJA uma oportunidade de se qualificar profissionalmente. Expressando sua situação atual, uma estudante disse em entrevista "Eu já não via mais possibilidade alguma de trabalhar na cidade em que moro, mas eu quis fazer esse curso por que se surgir uma oportunidade em qualquer outra cidade eu vou para trabalhar" (Estudante 9).

Na maioria das entrevistas, os estudantes disseram que buscaram a EJA porque se sentiam excluídos socialmente, sendo que muitas vezes sentiam a necessidade de dar como exemplo aos seus filhos a importância do estudo na vida das pessoas. Ainda para os que trabalham formalmente, voltar a estudar para eles era também uma maneira de estar inserido na sociedade, uma vez que eles atribuem ao estudo a possibilidade de "ser alguém na vida".

Foi como disse o estudante que trabalha em uma indústria como auxiliar de serviços gerais "Eu não estudei e hoje trabalho de serviços gerais, mas todos os dias eu digo a meu filho que ele estude para ser alguém na vida, que não seja como eu. Mas eu não desisti e voltei para estudar, pois tenho que dar bom exemplo" (Estudante 14).

Muitos estudantes relataram ter deixado à escola na idade regular para trabalhar e ajudar a família. Outros sinalizaram a questões como gravidez na adolescência, perda dos pais precocemente e até mesmo abuso sexual e dependência química. Uma estudante que cria sozinha, as três filhas menores, disse: "Eu tive minha primeira filha com 15 anos e depois as outras duas nasceram quando ela tinha 6 anos... o pai não arca com nada, mas eu me viro como diarista durante o dia e a noite venho estudar por que eu vou conseguir um trabalho bom para ajudar minhas filhas que gostam de estudar e me dão muito orgulho". (Estudante 8)

Sobre os desafios de retornar as salas de aula, alguns disseram que em alguns momentos faltam a aula por causa do transporte público que é 
municipal e atende ao calendário da prefeitura e não do governo federal, já que estamos falando de um curso que acontece no IFBA. Um estudante que mora em uma cidade que fica localizada a $25 \mathrm{~km}$ de distância da cidade de Santo Amaro explicou o seguinte: "Eu saio do trabalho lá onde eu moro e não dá tempo de vir no escolar, daí eu pego a minha moto e venho, mas como a aula acaba 10 horas da noite, quando está chovendo eu não venho. Por isso no inverno eu falto muito e fui reprovado já em dois módulos" (Estudante, 15).

Percebemos também pelos relatos que, em alguns casos, os estudantes saem do trabalho e não vão à escola por que não têm como se alimentar de forma que consigam permanecer em sala de aula durante 4 horas. A não ser no período em que a instituição estava oferecendo lanche. Relataram a partir desta investigação que antes de alguns cortes do governo, quando a instituição oferecia lanche para os estudantes do noturno, que eles aumentaram suas frequências porque sabiam que era uma refeição a mais para eles.

Outra perspectiva da EJA na vida de alguns estudantes é também a socialização, alguns relataram que vão à escola para além de estudar conhecer pessoas e fazer amizade. Como disse uma estudante que mora a 30 metros do campus "No começo tive muita dificuldade, pensei em desistir, mas me familiarizei com os meus colegas e é um lugar que eu gosto de vir à noite para aprender mais e distrair minha cabeça. Aqui aprendo também com os meus colegas, são gente como eu." (Estudante 8).

A importância de saber individualmente o que cada uma dessas pessoas pensa a respeito do papel da EJA em sua vida, nos permite perceber que apesar das peculiaridades de cada indivíduo, que fez parte desta pesquisa, todos têm desejos que atendem ao mesmo objetivo que é a ascensão pessoal.

Seja em busca de um trabalho, de reaprender conteúdos, de dar exemplo para os filhos, mas todos buscam por sua dignidade e pelo direito que a EJA os oferece. E, além de todos os obstáculos, eles dizem que aquele espaço educacional os ensina muito mais do que conteúdo, os ensina o respeito pelo outro e a importância que cada um deles tem na vida.

Foi com base nas questões inicialmente apresentadas que direcionamos esta pesquisa, mas aprendemos que ainda que fundamentemos nossa investigação com teorias já discutidas, as pessoas quando são investigadas sempre vão nos surpreender com seus relatos e isso vai acabar fazendo com que possamos repensar até mesmo, as questões da pesquisa que estamos desenvolvendo. Isso não nos tira o foco, abre nossos olhares para outras possibilidades de problemas assim como de outras soluções.

Descobrir que não existe um só perfil de aluno da EJA, nos faz acreditar 
também que não existe um só perfil de aluno de nenhuma outra modalidade de ensino, afinal, cada pessoa tem uma história e possivelmente ela é quem define que aluno esta pessoa será, não a modalidade. Desta forma, nossa perspectiva de investigação e de intervenção também acabam mudando, quando conhecemos de perto algumas realidades.

Os resultados das análises das entrevistas e dos questionários, da pesquisa qualitativa com dispositivo autobiográfico, apontaram que a desmotivação é uma das categorias que mais toma conta dos estudantes da EJA. Por isso, eles não se sentem valorizados. Isso implica na evasão, na não representatividade da modalidade e principalmente na falta de retorno às pesquisas sobre os resultados da EJA.

Isso não quer dizer que essa modalidade de ensino não faça sentido, muito pelo contrário, quer dizer que ela não está sendo colocada em prática com a sua devida finalidade, que é oportunizar, incentivar e emancipar pessoas que precisam que os seus direitos, negados na infância e na adolescência se façam valer, saiam do aspecto legal e se tornem um fato social, educacional, político e cultural. Não se trata de uma oportunidade e sim de um direito humano.

\section{Considerações finais}

Trazemos os resultados e as informações desta pesquisa deixando claro que a oferta da EJA precisa mudar, para abraçar a causa de mais de 11 milhões de pessoas analfabetas que vivem no Brasil.

Por isso, não podemos perder de vista que a EJA está em constante mudança e as pessoas que a fazem acontecer também e que fazemos parte de uma sociedade contemporânea com tantos problemas sociais, econômicos e políticos, onde as pessoas lutam todos os dias pelos seus direitos, sejam eles educacionais ou de outras vertentes.

A pesquisa autobiográfica foi importante porque permitiu ouvir os estudantes a partir de diversos pontos de vista da realidade educacional e social. Em se tratando da EJA, essa foi a melhor forma de investigar, para perceber e analisar as diferentes situações em que os estudantes que atuam nessa modalidade de ensino são obrigados a viver.

As intervenções apresentadas à comunidade da EJA após os procedimentos de análise das informações coletadas foi primeiramente a de conscientizar os estudantes de que a EJA é um direito deles e são eles quem tem que iniciar a luta por ela. Obviamente, essa luta implicará na conscientização 
dos demais participantes desta modalidade de ensino.

Seguidamente apresentamos aos docentes os relatos dos estudantes e alguns ficaram surpresos com a representação do seu papel de professor, destacamos a importância do cumprimento da carga-horária em sala de aula e destacamos a necessidade de ele reavaliarem as suas práticas docentes para com a EJA.

Concluímos essa investigação destacando o quanto precisamos melhorar as condições de oferta e de práticas pedagógicas transformadoras, na sala de aula dos alunos da EJA. Há toda uma esperança dos professores e dos alunos que dias melhores virão. Precisamos lutar pelos nossos direitos e influenciar outras pessoas de forma positiva de modo que elas também lutem pelos seus direitos. A partir dessas movimentações que surgem as ideais de criação de políticas públicas educacional de atendimento a comunidade que permitem que as pessoas tenham direito a educação.

\section{Referências}

CHARLOT, Bernard, (2000). Da relação com o saber: elementos para uma teoria. Porto Alegre: Artemed.

FERRAROTI. F. Sobre a autonomia do método biográfico. In: NÓVOA, António; FINGER, M. (Orgs). O método (auto) biográfico e a formação. Natal, RN: EDUFRN; São Paulo: Paulus, 2010.

FREIRE, P. Pedagogia do oprimido. 56. ed. Ver. E atual. Rio de Janeiro: Paz e Terra, 2013.

HADDAD. S., DI PIERRO. M. C. A EJA na agenda nacional de políticas educacionais: expectativas e frustrações da primeira década do terceiro milênio. Cad. Cedes, Campinas, v. 35, n. 96, p. 197-217, maio-ago., 2015

IBGE - INSTITUTO BRASILEIRO DE GEOGRAFIA E ESTATÍSTICA. PNAD Contínua 2017: número de jovens que não estudam nem trabalham ou se qualificam cresce 5,9\% em um ano - São Paulo. Rio de Janeiro, 2017(estatísticas sociais)

MACHADO, Maria Margarida. A educação de jovens e adultos após 20 vinte anos da Lei no 9.394, de 1996. Revista Retratos da Escola, Brasília, v. 10, n. 19, p. 429-451, jul./dez. 2016. Disponível em: http://www.esforce.org.br/

MINAYO, M. C. S. O desafio do conhecimento: pesquisa qualitativa em saúde. São Paulo: Hucitec, 2013. 
MINAYO, Maria Cecília de Souza. O desafio do conhecimento. 11 ed. São Paulo: Hucitec, 2008.

MINAYO, M. C. S. Pesquisa Social: Teoria, método e criatividade. Rio de Janeiro: Vozes, 2016. (Série Manuais Acadêmicos). 95p.

NÓVOA, A.; FINGER, M. (Org.). O método (auto) biográfico e a formação. Natal, RN: EDUFRN; São Paulo: Paulus, 2010.

PAIVA, Jane. Aprendizados ao longo da vida: sujeitos, políticas e processos. Rio de Janeiro: EDUERJ, 2019. 228p.

PASSEGGI, Maria da Conceição. Narrar é humano! Autobiografar é um processo civilizatório. In: PASSEGGI, Maria da Conceição; SILVA, V. B. (Orgs.). Invenções de vidas, compreensão de itinerários e alternativas de formação. São Paulo: Cultura Acadêmica, 2010.

SANTOS, Boaventura de Souza. O fim do império cognitivo: a afirmação das epistemologias do Sul. BH: Autêntica Editora, 2019. 478p.

SUESS, R; LEITE, C. Paulo Freire e humanismo em educação: contribuições a partir de uma perspectiva geográfica. Geosaberes, Fortaleza, v. 8, n. 16, p. 94105, set./dez. 2017. 